\section{A psychiatry in ascent: Nigeria revisited*} Dear Sirs

In a recent article, Morrison' lamented the 'decline of psychiatry', taking his examples (except one) from the UK. Observations in the Federal Republic of Germany during the 70 s and early 80 s could have incited similar sighs and complaints of psychiatry's susceptibility to ideology. ${ }^{2}$ But during a visit to psychiatric institutions in Nigeria in January 1985 I was privileged to see a psychiatry in ascent. Set against earlier experiences which extend back to 1961 and include a term as WHO Visiting Professor from 1968-1973, from ten years of working in Nigeria I found that the development of psychiatry in Nigeria since I first became acquainted with it twenty-four years ago is almost unbelievable. The increase in the numbers of professional staff speaks for itself; psychiatrists have increased from four to fifty, psychiatric nurses from less than thirty to over 1,000; psychiatric social workers and clinical psychologists from zero to several dozens each.

Despite sometimes marked differences in personalities, it is impressive to observe a distinct conformity in clinical practice: limiting the use of psychopharmacopoeia to a few brands familiar to everybody; applying ECT without hesitation when indicated by internationally accepted criteria; carrying out individual and group psychotherapy, occupational therapy; aiming at the therapeutic community; and, following the recommendations of modern developments, trying to incorporate psychiatry into primary and secondary health care services wherever feasible.

I was most impressed by the high esteem psychiatry enjoyed from the other medical specialties, including general medical practice, by the eagerness of medical students and student nurses to acquire a better understanding of mental health problems, and by the able performance of the trainees in psychiatry. I received at my request more than seventy reprints of published papers from Nigerian psychiatrists of the last decade, a fraction of those actually published in scientific journals. Some of the research, as well as questions raised in my discussions, centred around the position of traditional medicine in future health services. There seems agreement that differentiation must be made between 'real' traditional healers, knowledgeable and guarding ancient Wisdom, and the increasing number of self-appointed 'transitional healers' who often are more interested in a quick gain than in the welfare of the patient.

In addition to clinical activities and research results I was impressed by the very high professional standard of undergraduate teaching. All University departments have succeeded in extending the teaching time far beyond the posting of one week when it began in 1957 and two weeks after 1967, to eight weeks in most medical schools, including, besides formal teaching sessions, participation in in- and out-patient care as well as postings to out-posts connected with primary health care activities.

I thought remarkable the willingness to discuss openly, even

I am grateful to the Auswartige Amt of the Fed. Rep. Germany for providing a travel grant, and to my hosts for providing board. lodging. and local transport in Nigeria. controversial subjects, and the ability to contribute to a solution: this was displayed in all discussions I was privileged to hold with twenty-five of the fifty psychiatrists working in Nigeria at present.

It was a great satisfaction to learn of the regular meetings of the Association of Psychiatrists in Nigeria over more than fifteen years, a record hardly beaten by another psychiatric association in Africa south of the Sahara. Maybe most significant for a psychiatry in ascent is the opportunity for young doctors to obtain a professional qualification in Nigeria. For many years Nigerian doctors, even after being able to obtain their first degrees in Nigeria, had to go for further training to the Maudsley Hospital, to Edinburgh, to other psychiatric institutions in the UK or in the USA, or even to Australia, Germany and other countries. Now training in psychiatry can be done in Nigeria; psychiatry in Nigeria has come of age. Already it has contributed to the progress of psychiatry in the world, e.g. by Lambo's Aro Village, and it will continue to serve as an example to other Third World countries; but it may also help Western psychiatry to trust again its foundation in the sciences, natural and social. and in the humanities.

I am grateful to tate to have been connected for almost a quarter of a century with Nigeria and her 'psychiatry in ascent'.

\section{Wichernhaus}

Alexander Boroffka

\section{D-2300 Kiel 14, W Germany}

\section{RefEREnCES}

IMorrison. A. (1985) Psychiatry in decline-a personal view. Bulletin of the Royal College of Psychiatrists, 9, 4-7.

2MatusseK. P. (1976) Die Ideologieanfalligkeit der Psychiatrie. In Standorte der Psychiatrie. (Eds. H. Hippius and H. Lauter). Munchen: Urban \& Schwarzenberg.

\section{Pre-registration house officer posts in psychiatry}

\section{Dear Sirs}

With changes in the regulations of the General Medical Council, it has been possible to introduce a variation in the standard pattern of six months' medicine and six months' surgery during the pre-registration year. In August 1981 a rotation of four months' medicine, four months' surgery and four months' psychiatry was introduced at the Northern General Hospital, Sheffield. Following this rotation a second series of posts was introduced in August 1984. This report summarizes the views of the incumbents of the posts, their work on the wards and their future intentions concerning a medical career.

There have now been fifteen holders of the posts, selected from Sheffield graduates applying during their final year of medical training. Two common reasons for acceptance are those students who see their future in general practice and those who are considering psychiatry as a career, but would like experience at graduate level, before making a final decision. However, other factors which may govern the choice of the student include the guarantee of a twelve-month post in 